\title{
Clinical courses and predictors for rebleeding in patients with peptic ulcers and non-bleeding visible vessels: a prospective study
}

Hwai-Jeng Lin, Chin-Lin Perng, Fa-Yauh Lee, Chen-Hsen Lee, Shou-Dong Lee

\begin{abstract}
Detailed characterisation of non-bleeding visible vessels in terms of colour, size evolution, and time of rebleeding is important in determining the natural history of these lesions. The colour and size of non-bleeding visible vessels were observed endoscopically every day for three days and then every other day until rebleeding or flattening of visible vessels occurred in 140 patients. Rebleeding happened in $61(44 \%)$ patients. Of them, $59(97 \%)$ rebled within 72 hours. Flattening of visible vessels happened in $79(56 \%)$ patients and 77 of $79(98 \%)$ had flattening of visible vessels within 72 hours. Rebleeding rate increased with increasing length of exposed vessels $(r=0.96, p<0.001)$. Coffee ground fluid or blood retention in the stomach and ulcer size $\geqslant 2.0 \mathrm{~cm}$ were independent predictors for rebleeding using multivariate analysis. It is suggested that patients with non-bleeding visible vessels and independent predictors for rebleeding may need early aggressive treatment.

(Gut 1994; 35: 1389-1393)
\end{abstract}

Peptic ulcer bleeding stops spontaneously in $70-80 \%$ patients. ${ }^{1}$ The remaining patients represent a high risk group requiring prompt identification and treatment to offset a high morbidity and death rate. There is consensus that patients who have peptic ulcers with spurting or oozing haemorrhage need active treatment. ${ }^{1}$ In contrast, patients with peptic ulcers without stigmata of recent haemorrhage do not need any further treatment. ${ }^{1}$

Controversy exists concerning the need for invasive treatment for patients with peptic ulcers and non-bleeding visible vessels (NBVVs). The rebleeding rates for them may vary from 0 to $100 \%$ with an average of $40-50 \%$ in most reports. ${ }^{2-11}$ Endoscopic haemostatic treatment has been shown to be beneficial in patients with NBVVs in terms of rebleeding ${ }^{12-17}$ and needs of surgical intervention. ${ }^{12-14}$ Conflicting results, however, have also been reported. ${ }^{3} 18$ In addition, visible vessels with fresh clots or bare visible vessels are considered to be only a moderate or low risk for rebleeding by some authors. ${ }^{6} 19$ Therefore, if it is possible to differentiate between patients of high and low rebleeding risks, aggressive treatment can be given accordingly.

Predictors for rebleeding are the most important concerns in peptic ulcers with NBVVs. Apart from endoscopic Doppler ultrasound, the prediction of recurrent haemorrhage relies mainly on clinical and endoscopic criteria. ${ }^{19-22}$ The factors related to blood loss (for example, haemodynamic instability, haematemesis or red stools) are the chief clinical predictors. Endoscopic variables (for example, coffee ground fluid in the stomach, overlying blood clots in the ulcer base, and presence of a visible vessel) are the other important predictors.

In most reports, there was no stratification of visible vessels by colour, size or presence of overlying clot. ${ }^{19}$ The above variables may play important parts in predicting rebleeding. The purposes of this study are twofold: firstly, to present detailed length and colour evolutions of exposed NBVVs; secondly, to find independent predictors for rebleeding in patients of peptic ulcers with NBVVs so they can be treated promptly.

\section{Methods}

Patients with recent upper gastrointestinal bleeding were accepted for this study if a NBVV was seen at an ulcer base during an emergency endoscopic examination after resuscitation. The clinical aspect concerning NBVVs was discussed with the patients and written informed consent was obtained before the trial. Surgeons were informed of the entry of the patients to the study. The study was approved by the clinical research committee of the Veterans General Hospital, Taipei.

Patients were excluded from the study if (a) they refused to give written informed consent, (b) continued bleeding because of malignancy, (c) bleeding tendency (platelet count $\leqslant 50000 / \mathrm{mm}^{3}$, prothrombin time less than $30 \%$, or taking anticoagulant), or (d) tightly adherent blood clots that could not be removed.

All patients received an endoscopic examination at the hospital within 24 hours of arrival. Before endoscopic examination, nasogastric lavage was given to them every two hours. All diagnostic endoscopies and haemostatic treatments were performed by Lin and Perng who have at least 5000 patients experience in endoscopic examinations and 300 patients experience in therapeutic endoscopy.

Gastric fluid (clear, coffee ground or bloody) was recorded at endoscopy. Gentle washing technique was applied to remove blood and adherent clots to adequately observe 
the ulcer base. A visible vessel was defined as a discrete protuberance within the ulcer crater that had recently bled. The length of exposed NBVVs and peptic ulcers were measured by an endoscopic meter (Olympus M2-4K). We took at least six photographs for NBVVs at entry and in follow up endoscopies.

The patients' vital signs were checked every hour for 12 hours, every two hours for another 12 hours, every four hours for a subsequent 24 hours until they became stable, and then four times daily. Shock was defined as systolic pressure less than $100 \mathrm{~mm} \mathrm{Hg}$ and a pulse rate greater than $100 \mathrm{bpm}$. The haemoglobin and packed cell volume values were checked every day, and a blood transfusion was given if the haemoglobin concentration dropped to less than $9 \mathrm{~g} / \mathrm{dl}$ or if vital signs deteriorated. $\mathrm{H}_{2}$ Blockers (ranitidine $150 \mathrm{mg}$ every 12 hours or cimetidine $300 \mathrm{mg}$ every six hours intravenously) were given routinely during the stay in hospital.

A nasogastric tube was inserted and irrigated with water every two hours for every patient until occurrence of rebleeding or flattening of NBVVs. Endoscopy was performed every day for three days, then every other day until rebleeding or flattening of NBVVs occurred. If the NBVVs flattened, the patient was discharged and followed up at the outpatient department every week. An endoscopic examination was performed every month for three months. $\mathrm{H}_{2}$ Blockers (ranitidine $150 \mathrm{mg}$ or cimetidine $400 \mathrm{mg}$ twice daily) were given orally to every patient for at least two months at the outpatient department.

Rebleeding was suspected if a patient had fresh blood in the stomach six hours after entry to the study, presence of unstable vital signs, and continued tarry, bloody stools or haematemesis. We performed an emergency endoscopy for these patients. If active bleeding or a fresh blood clot was found at the ulcer base, rebleeding was confirmed and aggressive treatment was given immediately.

We performed endoscopic haemostatic treatment (adrenaline with or without pure

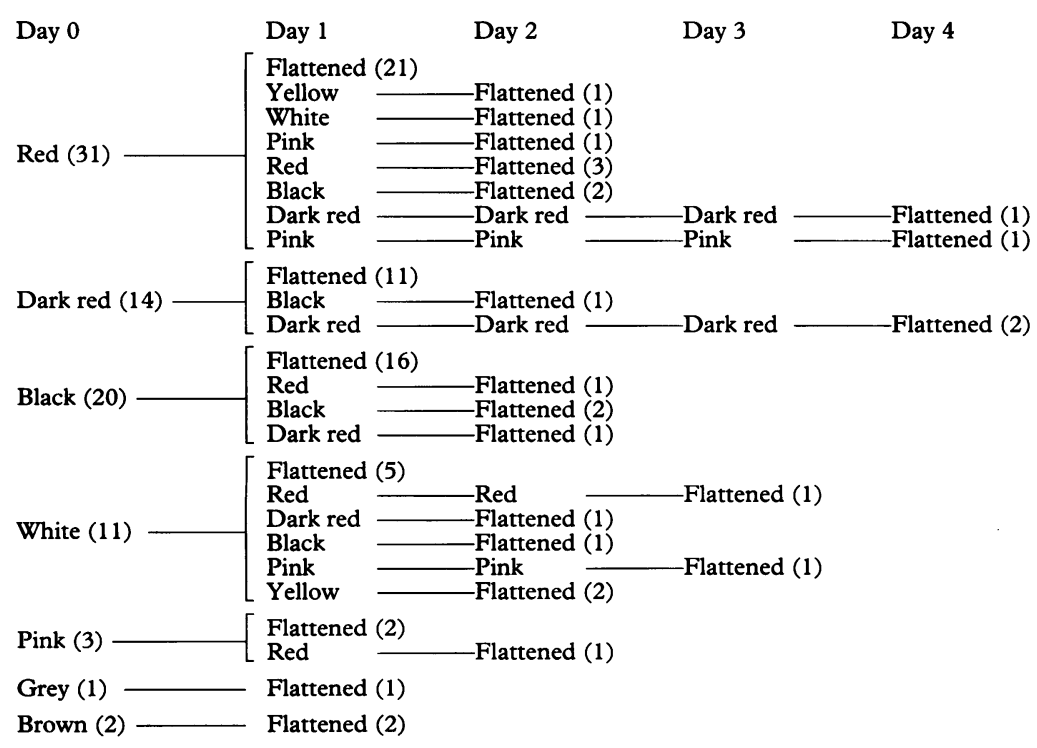

Figure 1: Colour evolution of the 82 visible vessels (79 patients) that did not rebleed. Numbers in parentheses show numbers of visible vessels. alcohol injection, heater probe thermocoagulation) for those who experienced rebleeding. If patients refused endoscopic treatment, surgical intervention was conducted.

A positive history of non-steroid antiinflammatory drug (NSAID) ingestion was defined as $>1$ tablet/day NSAID ingestion within seven days of admission for peptic ulcer bleeding. Positive cigarette smoking was defined as $\geqslant 10$ cigarettes per day for at least one year. Positive alcohol drinking was defined as $\geqslant 40 \mathrm{~g} /$ day alcohol consumption for at least six months.

Three groups of different severity of comorbid illness were classified as: group 1, no pre-existing illness; group 2 , stable pre-existing illness (such as ischaemic heart disease, well controlled hypertension, diabetes mellitus, cardiac failure, cirrhosis of liver, cerebrovascular disease, chronic airway disease), or gastrointestinal bleeding after an uncomplicated procedure (such as cholecystectomy, repair of fracture); group 3, serious intercurrent illness (such as decompensated heart disease, decompensated liver disease, active malignancy, severe sepsis, dialysis dependent acute renal failure, multiple injuries) or gastrointestinal bleeding when acutely ill after a major operation (such as cardiac surgery or repair of aortic aneurysm). ${ }^{23}$

We used the $\chi^{2}$ test with or without Yates's correction, or Fisher's exact test, when appropriate, to compare the rebleeding rates in 21 clinical and endoscopic variables. These 21 variables were: age ( $<60$ or $\geqslant 60$ years), sex, initial manifestation (haematemesis/melaena or melaena only), onset of bleeding (before admission or during hospital stay), duration of sign for peptic ulcer bleeding $(<2$ or $\geqslant 2$ days), previous peptic ulcer bleeding history, location of bleeding vessel (stomach, duodenum, anastomotic site), overlying clot, gastric content (clear, coffee ground, bloody), vital signs (stable, pulse rate $>100 \mathrm{bpm}$, shock), volume of blood transfusion at entry $(<500$ or $\geqslant 500 \mathrm{ml})$, haemoglobin $(<10$ or $\geqslant 10 \mathrm{~g} / \mathrm{dl})$, blood urea nitrogen $(<30$ or $\geqslant 30$ $\mathrm{mg} / \mathrm{dl}$ ), history of NSAID ingestion, cigarette smoking, alcohol consumption, number of comorbid illness, severity of comorbid illness, ulcer size $(<2.0$ or $\geqslant 2.0 \mathrm{~cm})$, length of exposed NBVVs $(<3$ or $\geqslant 3 \mathrm{~mm}$ ), colour of NBVVs. Multivariate analysis was tested with stepwise logistic regression (BMDPLR) to find independent predictors of rebleeding. A probability value of less than 0.05 was considered significant.

\section{Results}

Between March 1991 and July 1992, a total of 19712 patients received an oesophagogastroduodenoscopic examination at our division. Of these, 986 complained of haematemesis or tarry stool, or both. Six hundred and ninety four patients had peptic ulcers. The following patients were excluded from the study because of: tightly adherent blood clots $(n=24)$, malignancies with bleeding $(n=22)$, receiving anticoagulants $(n=10)$, unable to give written 


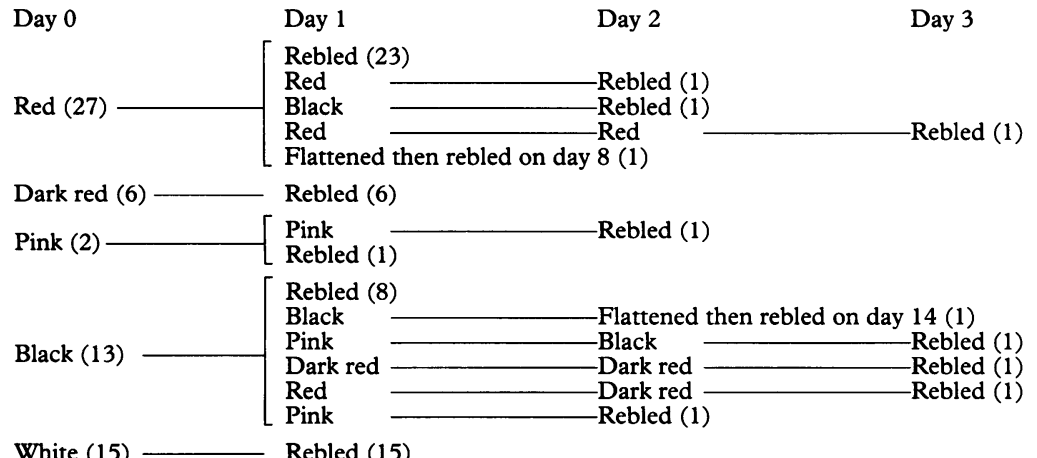

White (15) - Rebled (15)

Figure 2: Colour evolution of 63 visible vessels (61 patients) that rebled. Numbers in parentheses show numbers of visible vessels.

informed consent $(n=16)$, and unable to complete follow up $(n=18)$. Of the remaining 604 patients with peptic ulcers, 120 had active bleeding, 140 had NBVVs (with 145 NBVVs), 230 had flat black or red spots at the ulcer bases, and 114 had clean ulcer bases. The age of these patients was 63 (14) (mean (SD), range: $23-85$ ) years, male to female ratio was $131 / 9$.

In our series, $135(96 \%)$ cases had one visible vessel in one ulcer. There were, however, two visible vessels per ulcer in five patients. Of these five patients, two suffered from rebleeding within one day, whereas three others had flattening of visible vessels within one day. In 140 patients with NBVVs, 61 patients (44\%, with 63 visible vessels) were found to rebleed. They still had visible vessels present at the time of rebleeding. The rebleeding episodes occurred within 24 hours in 51 patients (84\%, with 53 visible vessels) and within three days in 59 patients $(97 \%$, with 61 visible vessels). It is interesting to note that two patients (3\%) still rebled on day 8 and day 14, respectively, after flattening of visible vessels. Flattening of visible vessels occurred in 79 patients (with 82 visible vessels). Of these, the visible vessels flattened within one day in 55 patients (70\%, with 58 visible vessels), and within three days in 77 patients $(98 \%$, with 80 visible vessels).

With univariate analysis, statistically significant factors adversely affecting rebleeding were: coffee ground fluid retention in the stomach $(\mathrm{p}<0.05 v$ clear $)$, blood retention in the stomach $(\mathrm{p}<0.0001 v$ clear $)$, shock $(\mathrm{p}<0.05 v$ stable), volume of blood transfusion $\geqslant 500 \mathrm{ml}(\mathrm{p}<0.05)$, an admission haemoglobin $<10 \mathrm{~g} / \mathrm{dl}(\mathrm{p}<0.05)$, an ulcer size $\geqslant 2.0 \mathrm{~cm}$

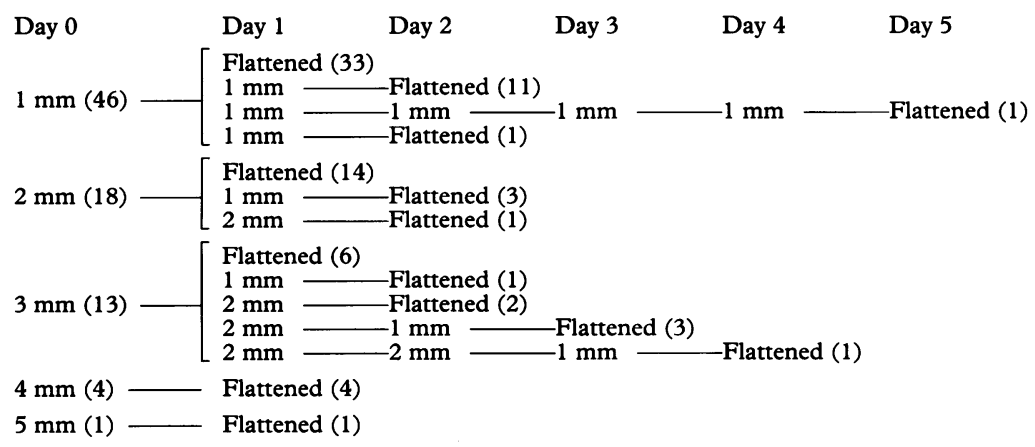

Figure 3: Size evolution of 82 visible vessels (79 patients) that did not rebleed. Numbers in parentheses show numbers of visible vessels. $(\mathrm{p}<0.01)$, and an exposed NBVV length $\geqslant 3 \mathrm{~mm}(\mathrm{p}<0.05)$. With multivariate analysis, coffee ground fluid (odds ratio: $3.538,95 \%$ confidence intervals: 1.41 to $8 \cdot 85$ ) or blood retention (odds ratio: $11.53,95 \%$ confidence intervals: 2.83 to $47 \cdot 1)$ in the stomach, and ulcer size $\geqslant 2.0 \mathrm{~cm}$ (odds ratio $v$ ulcer $<0.5 \mathrm{~cm}: 5 \cdot 239,95 \%$ confidence intervals: 0.816 to 33.6 ) emerged as independent predictors for rebleeding.

With regard to the colour of NBVVs at entry to the study, we found seven different colours (red, dark red, black, white, pink, grey, and brown) in the ulcer bases (Figs 1 and 2). Red and dark red NBVVs (78 of $145,54 \%$ ) were most commonly found, followed by black NBVVs (33 of 145, 23\%), and white NBVVs (26 of $145,18 \%$ ). The rebleeding rate was highest in the white colour NBVVs (15 of 26, $58 \%$ ) followed by red ( 27 of $58,47 \%$ ), pink ( 2 of $5,40 \%)$, black ( 13 of $33,40 \%)$, dark red ( 6 of $20,30 \%$ ), brown ( 0 of 2 ), and grey NBVVs (0 of 1). No significant difference of rebleeding rates was found in the diverse colour NBVVs. There was no constant colour evolution for NBVVs in our series.

The length of the exposed NBVVs varied from one $\mathrm{mm}$ to seven $\mathrm{mm}$. NBVVs of one $\mathrm{mm}$ and two $\mathrm{mm}$ length were most commonly found (102 of 145, 70\%) (Figs 3 and 4). Rebleeding rates for one $\mathrm{mm}$, two $\mathrm{mm}$, three $\mathrm{mm}$, four $\mathrm{mm}$, five $\mathrm{mm}$, six $\mathrm{mm}$, seven $\mathrm{mm}$ NBVVs were $34 \%$ (24 of 70 ), $44 \%$ (14 of 32 ), $52 \%$ (14 of 27 ), $60 \%$ (6 of 10 ), $67 \%$ (2 of 3 ), $100 \%$ ( 2 of 2 ), and $100 \%$ ( 1 of 1$)$, respectively. The rebleeding rate increased with increasing length of exposed NBVVs $(r=0.96, \mathrm{p}<0.001)$.

Forty eight of 61 rebleeders received endoscopic treatment (22: adrenaline injection, 22: adrenaline plus pure alcohol injection, and four: heater probe thermocoagulation), 11 received surgery, one received pitressin infusion, and one received medical treatment.

A total of 10 patients with NBVVs died in this series. One died of continuous bleeding before surgical intervention, and five rebleeding patients died of surgical complications (two complicated with respiratory failure, one with heart failure, and two with gall bladder gangrene). Four patients who had flattening of NBVVs died of unrelated illness (one cerebrovascular accident, one lymphoma, one respiratory failure, and one cachexia).

In non-rebleeders, 63 patients $(72 \%)$ received an endoscopic follow up for at least two months. Fifty of them $(79 \%)$ had scars at the previous ulcer location two months later. We could not follow up 43 of these patients for 18 (8) months (mean (SD)). A total of nine rebleeding episodes occurred in six patients during follow up. Eight rebleeding episodes subsided spontaneously. One rebleeding episode subsided after heater probe thermocoagulation.

\section{Discussion}

In recent years, attention has been paid to the finding of NBVVs in peptic ulcer 


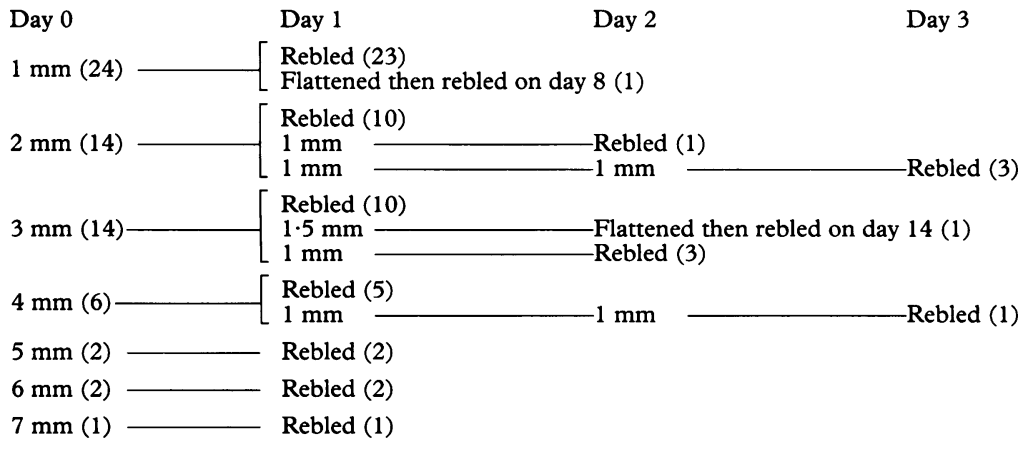

Figure 4: Size evolution of 63 visible vessels (61 patients) that rebled. Numbers in parentheses show numbers of visible vessels.

bases, because a life threatening haemorrhage originates from an eroded artery rather than a non-arterial bleeding, which will probably stop by itself. ${ }^{824}$ In our series, the likelihood of NBVVs in peptic ulcers rebleeding was $23 \%$ (140 of 604), which was comparable with other findings. $5925-27$

Predicting rebleeding in peptic ulcers with NBVVs is no doubt important for clinicians because of a six to 12 -fold increase in mortality in rebleeders. ${ }^{28-31} \mathrm{~A}$ combination of clinical and endoscopic risk factors can provide a more reliable prediction of rebleeding than individual criteria. ${ }^{11920}$ For example, endoscopic stigmata associated with hypotension had a much higher rebleeding rate than that of stigmata without hypotension. ${ }^{732}$ Different timing of endoscopy has undoubtedly resulted in a diverse occurrence of NBVVs in published reports. ${ }^{625}$ We performed endoscopy within 24 hours in every case to avoid this problem. Also, to avoid interobserver variation, the findings of NBVVs were all confirmed by two experienced endoscopists.

A logical evolution of the colour of NBVVs of stigmata of haemorrhage with bleeding peptic ulcer has been proposed by Johnston. ${ }^{19}$ The arterial bleeding sequence is: a large red clot contiguous with a visible vessel develops, then a small red visible vessel, followed by a dark visible vessel, then a white visible vessel, and finally the clot disappears. In our series, the colour change of red visible vessels could be as many as six different colours on the next day if no rebleeding or flattening of visible vessels occurred. There was also no constant change for visible vessels of other colours. The hypothesis of red-black-white then disappearance of visible vessels should be revised.

The NIH Consensus Conference concludes that a red, blue, or purple visible vessel implies a high risk of rebleeding but there is less rebleeding with a white or black visible vessel. ${ }^{1}$ Our findings, however, were different in this study. Although it did not reach statistical significance, a white visible vessel carried a higher rebleeding rate $(15$ of $26,58 \%$ ) than those of other visible vessels. Black and red visible vessels had similar rebleeding rates (39\% v 47\%, respectively, $\mathrm{p}>0.05$ ).

Wara found two distinct visible vessels. A visible vessel associated with an overlying clot had a rebleeding rate of $24 \%$, while the rebleeding rate of a bare visible vessel was only $18 \%{ }^{6}$ In our series, visible vessels with or without adherent blood clots had similar rebleeding rates. It seems that an overlying clot is not a reliable predictor for rebleeding.

Bleeding may be severe with ulcers over the posterior duodenal bulb and high with ulcers over the lesser curvature of the stomach. ${ }^{33-36}$ Many endoscopists, however, do not agree that site is predictive of rebleeding. ${ }^{1}$ We saw a similar rebleeding rate for peptic ulcers with NBVVs over these locations.

Age, ${ }^{28} 29323738$ comorbid illness, ${ }^{29}$ history of peptic ulcer bleeding, ${ }^{29} 38$ haematemesis, ${ }^{39} 40$ unstable vital signs, ${ }^{7} 283238$ low haemoglobin on presentation, ${ }^{28} 293238$ large volume blood transfusion, ${ }^{28}$ ulcers located on the posterior wall of the duodenal bulb, ${ }^{3541}$ and ulcer size larger than one $\mathrm{cm}$ in diameter ${ }^{35} 41$ have been reported to be risk factors in rebleeding. In our series with multivariate analysis, only coffee ground fluid or blood retention in the stomach, and an ulcer size $\geqslant$ two $\mathrm{cm}$ were independent in predicting rebleeding.

Endoscopic Doppler ultrasound can identify a vessel and its velocity beneath the ulcer base more precisely. ${ }^{21}$ A positive Doppler signal discloses arterial flow and has been associated with an $80-90 \%$ rebleeding rate. $^{21} 22$ This method is, however, time consuming, not easily available, and not objective in interpretation. ${ }^{21}$

Most episodes (59 of $61,97 \%$ ) of rebleeding occurred within 72 hours in our series, which is compatible with other reports. ${ }^{31} 38$ The rebleeding rate was minimal $(2$ of $81,3 \%)$ after flattening of visible vessels. Therefore, three days of observation is critical for patients with NBVVs in the ulcer bases. The patients may be discharged early if NBVVs flattened.

In conclusion, most rebleeding episodes or flattening of NBVVs occurred within 72 hours of observation. Their colour evolutions could be multifarious. The rebleeding rates increased with increasing length of the exposed NBVVs. With multivariate analysis, independent predictors for rebleeding at endoscopy were: coffee ground fluid or blood retention in the stomach, and an ulcer size $\geqslant$ two $\mathrm{cm}$. We suggest endoscopic haemostatic treatment or surgery for patients with NBVVs who have any of the above independent predictors.

We thank Miss Shiau-Bey Jou for her expert assistance in statistical analysis. Part of this study was presented at the Digestive tical analysis. Part of this study was presented at the Digestive

1 Consensus conference. Therapeutic endoscopy and bleeding ulcers. $\mathcal{F} A M A$ 1989; 262: 1369-72.

2 Chang-chien CS, Wu CS, Chen PC, Lin DY, Chu CM Fang KM, et al. Different implications of stigmata of Fang KM, et al. Different implications of stigmata of Dig Dis Sci 1988; 33: 400-4.

3 Krejs GJ, Little KH, Westergaard LT, Hamilton JK, Spady DK, Polter DE. Laser photocoagulation for the treatmen of acute peptic ulcer bleeding: a randomized controlled clinical trial. N Engl f Med 1987; 316: 1618-21.

4 Domschke W, Lederer P, Lux G. The value of emergency endoscopy in upper gastrointestinal bleeding: review and analysis of 2014 cases. Endoscopy 1983; 15: 126-31.

5 Griffiths WJ, Neumann DA, Welsh JD. The visible vessel as an indicator of uncontrolled or recurrent gastrointestina hemorrhage. N Engl f Med 1979; 300: 1411-3. 
6 Wara P. Endoscopic prediction of major rebleeding - a prospective study of stigmata of hemorrhage in bleeding ulcer. Gastroenterology 1985; 88: 1209-14

7 Bornman PC, Theodorou NA, Shuttleworth RD, Essel HP, Marks IN. Importance of hypovolaemic shock and endoscopic signs in predicting recurrent haemorrhage from peptic ulceration: a prospective evaluation. $B M F 1985$; 291: $245-7$.

8 Swain CP, Storey DW, Bown SG, Heath J, Mills TN, Salmon PR, et al. Nature of the bleeding vessel in recurSalmon PR, et al. Nature of the bleeding vessel in recur-
rently bleeding gastric ulcers. Gastroenterology 1986; 90: rently bleed

9 Storey DW, Bown SG, Swain CP, Salmon PR, Kirkham JS, Northfield TC. Endoscopic prediction of recurren bleeding in peptic ulcers. $N$ Engl $\mathcal{f}$ Med 1981; 305: 915-6.

10 Freeman ML, Cass OW, Peine CJ, Onstad GR. The nonbleeding visible vessel versus the sentinal clot: natural history and risk of rebleeding. Gastrointest Endosc 1993; 39; 359-66.

11 Lin HJ, Lee FY, Tsai YT, Lee SD, Lee CH. What kind of non-bleeding visible vessel in a peptic ulcer needs aggressive therapy - a longitudinal observation. Endoscopy 1990 22: 8-11.

12 Laine L. Multipolar electrocoagulation in the treatment of active upper gastrointestinal hemorrhage: a prospective controlled trial. N Engl F Med 1987; 316: 1613-7.

13 Laine L. Multipolar electrocoagulation in the treatment of ulcers with non-bleeding visible vessels: a prospective, controlled trial. Ann Intern Med 1989; 110: 510-4.

14 Jensen DM. Heat probe for hemostasis of bleeding peptic ulcers: techniques and results of randomized controlled trial. Gastrointest Endosc 1990; 36: S42-9.

15 Panes J, Viver J, Forne M, Garcia-Olivares E, Marco C, Garau J. Controlled trial of endoscopic sclerosis in bleeding peptic ulcers. Lancet 1987; ii: 1292-4.

16 Fullarton GM, Birnie GG, Macdonald A, Murray WR Controlled trial of heater probe treatment in bleeding peptic ulcers. Br ₹ Surg 1989; 76: 541-4.

17 Matthewson K, Swain CP, Bland M, Kirkham JS, Bown SG, Northfield TC. Randomized comparison of Nd YAG laser, heater probe, and no endoscopic therapy for bleeding peptic ulcers. Gastroenterology 1990; 98: 1239-44.

18 Lin HJ, Lee FY, Kang WM, Tsai YT, Lee SD, Lee CH. Heat probe thermocoagulation and pure alcohol injection in massive peptic ulcer haemorrhage: a prospective, randomised controlled trial. Gut 1990; 31: 753-7.

19 Johnston $\mathrm{JH}$. Endoscopic risk factors for bleeding peptic ulcer. Gastrointest Endosc 1990; 36: S16-20.

20 Peterson WL Clinical risk factors. Gastrointest Endosc 1990, 36: S14-5.

21 Fullarton GM, Murray WR. Prediction of rebleeding in peptic ulcers by visual stigmata and endoscopic Doppler ultrasound criteria. Endoscopy 1990; 22: 68-71.

22 Matre K, Ødegaard S, Hausken T. Endoscopic ultrasound Doppler probes for velocity measurements in vessels in the upper gastrointestinal tract using a multifrequency pulsed Doppler meter. Endoscopy 1990; 22: 268-70.
23 Turner IB, Jones M, Piper DW. Factors influencing mortality from bleeding peptic ulcers. Scand $\mathcal{f}$ Gastroenterol 1991; 26: 661-6.

24 Osborn GR. The pathology of gastric arteries with special reference to fatal haemorrhage from peptic ulcer. Br F Surg 1954; 41: 585-94.

25 Vallon AG, Cotton PB, Laurence BH, Miro JRA, Oses JCS Randomized trial of endoscopic argon laser photocoagulation in bleeding peptic ulcer. Gut 1981; 22: 228-33.

26 Fleischer D. Etiology and prevalence of severe persistent upper gastrointestinal bleeding. Gastroenterology 1983; 84:

27 Rutgeerts P, Vantrappen G, Broeckaert L, Janssens J Coremans G, Geboes K, et al. Controlled trial of YAG laser treatment of upper digestive hemorrhage. Gastroenterology 1982; 83: 410-6.

28 Schiller KFR, Truelove SC, Williams DG. Haematemesis and melaena with special reference to factors influencing the outcome. BMF 1970; 2: 7-14.

29 Silverstein FE, Gilbert DA, Tedesco FI, Buenger NK, Persing J, and 277 members of the ASGE. The national ASGE survey on upper gastrointestinal bleeding. ASGE survey on upper gastroint

30 Jones FA. Haematemesis and melaena. Gastroenterology 1956; 30: 166-90

31 Jones PF, Johnston SJ, McEwan AB, Kyle J, Needham CD. Further haemorrhage after admission to hospital for gastrointestinal haemorrhage. $B M \mathcal{F} 1973$; 3: 660-4

32 Clason AE, Macleod DAD, Elton RA. Clinical factors in the prediction of further haemorrhage or mortality in acute upper gastrointestinal haemorrhage. Brf Surg 1986; 73: $985-7$.

33 Swain CP, Salmon PR, Northfield TC. Does ulcer position influence presentation or prognosis of acute gastrointestinal bleeding? Gut 1986; 27: A632.

34 Jensen HE, Hoffmann J, Jorgensen PW. High gastric ulcer. World F Surg 1987; 11: 325-32.

35 Kang JY, Nasiry R, Guan R, Labrooy S, Lim KP, Yap I, et al. Influence of the site of a duodenal ulcer on its mode of presentation. Gastroenterology 1986; 90: 1874-6.

36 Sheppard MC, Holmes GKT, Cockel R. Clinical picture of peptic ulceration diagnosed endoscopically. Gut 1977; 18: 524-30.

37 Allan R, Dykes P. A study of the factors influencing mortality rates from gastrointestinal haemorrhage. $Q \mathcal{F} \mathrm{Med}$ 1976; 45: 533-50.

38 Macleod IA, Mills PR. Factors identifying the probability of further haemorrhage after acute upper gastrointestinal urther haemorrhage after acute upper

39 Northfield TC. Factors predisposing to recurrent haemorrhage after acute gastrointestinal bleeding. $B M \mathcal{F}^{1971}$; 1 : $26-8$.

40 Wara $\mathrm{P}$, Stodkilde $\mathrm{H}$. Bleeding pattern before admission as a guideline for emergency endoscopy. Scand $\mathcal{f}$ Gastroenterol 1985; 20: 72-8.

41 Branicke FJ, Boey J, Fok PJ. Bleeding duodenal ulcer. A prospective evaluation of risk factors for rebleeding and death. Ann Surg 1990; 211: 411-8. 